\title{
A hybrid endoscopic technique to close tracheoesophageal fistula
}

\author{
Maoyin Pang, MD, PhD, Omar Mousa, MBBS, Monia Werlang, MD, Bhaumik Brahmbhatt, MBBS, \\ Timothy Woodward
}

Tracheoesophageal fistula (TEF) is a congenital or acquired pathologic entity characterized by an abnormal communication between the posterior aspect of the trachea and the anterior wall of the esophagus. Acquired TEF is a not uncommon adverse event secondary to mechanical ventilation, trauma, esophageal tumor, prior laryngectomy, or esophagectomy. ${ }^{1-3}$ Given the potential serious consequence of possible fatal pulmonary aspiration, prompt closure of TEFs is critical. Although an endoscopic approach to TEFs has been optimized over the past years, including endoscopic stent placement and over-the-scope clip system, ${ }^{4-5}$ recurrent TEFs remain a therapeutic challenge, with literature reporting up to $20 \%$ recurrence. ${ }^{6-7}$ Here we present a new hybrid approach with endoscopic management of an acquired TEF.

Our patient was a 56-year-old man with a history of laryngeal malignancy, who had undergone laryngectomy, permanent tracheostomy, and placement of a tracheoesophageal voice prosthesis 12 years earlier and who was referred to our clinic for possible endoscopic closure of his TEF. It was unclear when the fistula had formed, but it had been causing aspiration of both liquid and solid foods for several months, and the patient also reported expelled food from the tracheostomy stoma. A recent
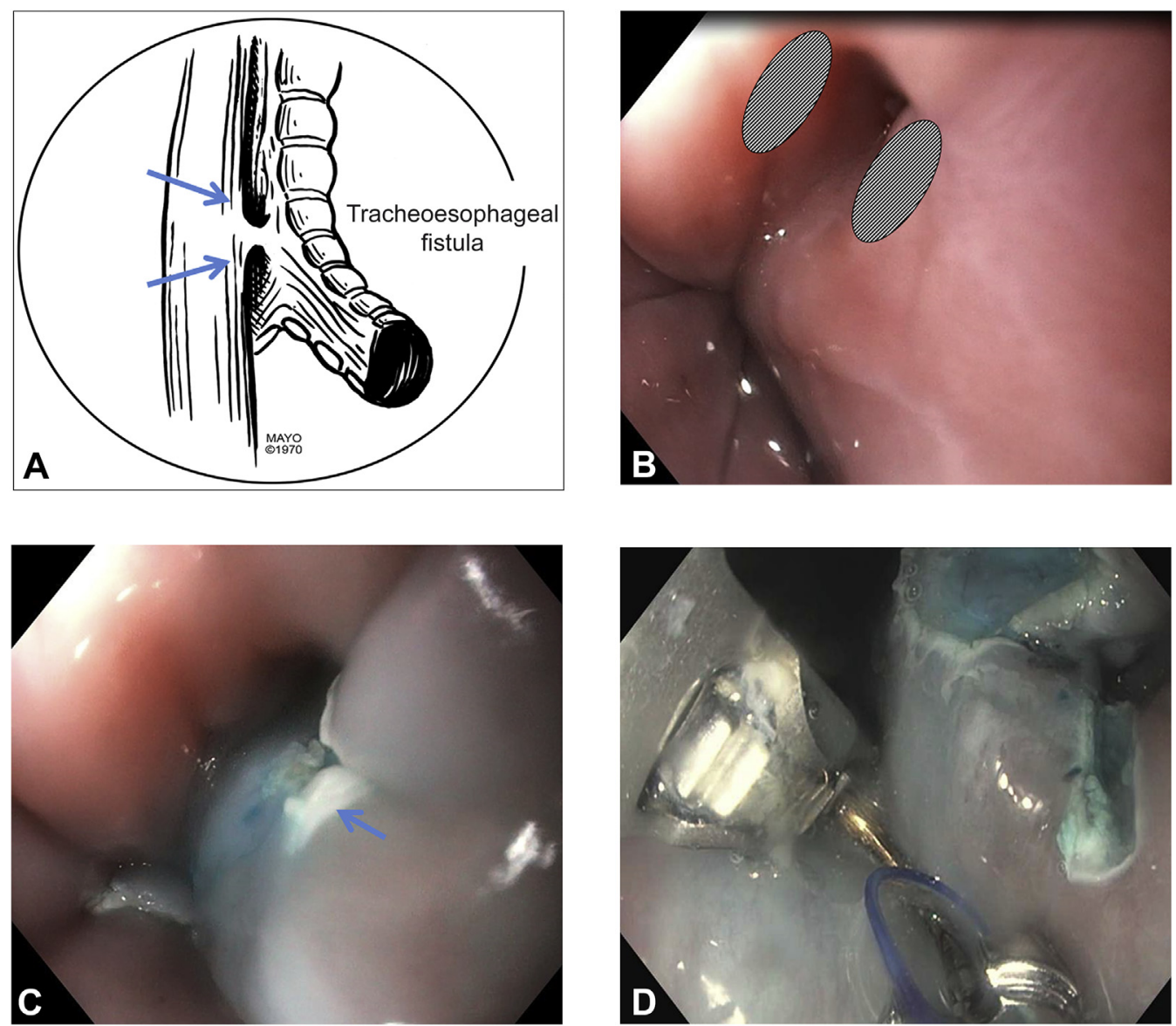

Figure 1. A, B, On the esophageal side of the fistula (blue arrows), mucosa surrounding the fistula opening (blue arrows, shaded area) were (C) resected by EMR, followed by (D) full-thickness suturing with assistance of an endsocopic suturing device. Used with permission of Mayo Foundation for Medical Education and Research. All rights reserved.

Written transcript of the video audio is available online at www.VideoGIE.org. 


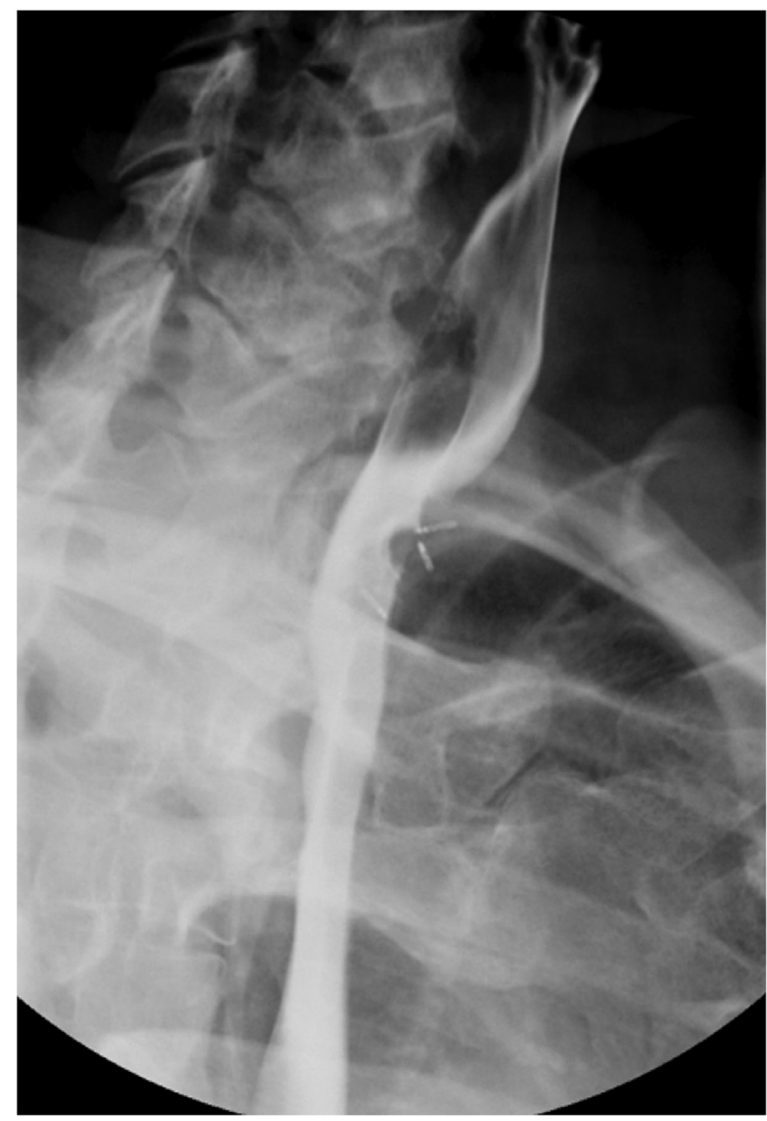

Figure 2. Follow-up esophagram confirming no extravasation of contrast material at the previous site of tracheoesophageal fistula.

video fluoroscopic swallow study showed leakage of barium into the trachea at the level of the stoma. An upper endoscopy showed a 5-mm fistula opening in the upper third of the esophagus, $20 \mathrm{~cm}$ from the incisors.

We decided to use a hybrid endoscopic technique to close the fistula (Video 1, available online at www. VideoGIE.org). This technique included 2-step procedures. First, we performed small mucosal resections surrounding the fistula opening on the esophageal side, to help tissue apposition, and the denuded tissues would decrease the chances of recurrence. Second, we used an endoscopic suturing device to close the denuded tissues with an over-thescope full-thickness suturing technique. We hypothesized that by resection, the squamous cell epithelialized mucosa with EMR, followed by full-thickness suturing, the denuded fresh tissue surface could subsequently enhance tissue regeneration and thus decrease the chances of recurrence.

A 1:10,000 solution of epinephrine with methylene blue was injected to raise the lesion. Snare mucosal resection was successfully performed surrounding the fistula opening on the esophageal side of fistula (Figs. 1A-1C). In addition, a brush was used to cause more abrasions inside the remaining fistula to enhance the healing of fistula. Subsequently, 3 ligatures were placed with endoscopic full-thickness suturing to successfully close the TEF (Fig. 1D). The procedure was successful, without any events or postprocedure adverse events. The patient was admitted for overnight observation. An esophagram on the following day confirmed that there was no extravasation of contrast material at the previous site of the TEF (Fig. 2). At the 30-day follow-up visit, the patient reported that he no longer had coughing spells during eating or drinking.

With this hybrid technique (ie, EMR of mucosa surrounding the fistula opening, followed by endoscopic full-thickness suturing; the fresh tissues were sutured into anastomosis with a fine closure for complete restoration), we expect that recurrence of a TEF could be significantly decreased or delayed. We have been able to accomplish suturing without an overtube, which greatly facilitates flexibility and access. It is essential to introduce the suturing device in a closed position and adjacent to the apex of the piriform sinus. We recommend using interrupted sutures rather than continuous sutures to minimize the possible subsequent stricture. This technique could be an alternative technique to achieve the endoscopic closure of chronic fistula secondary to a benign cause. It can even be considered to be applied to other types of chronic fistula. A prospective study comparing alternative techniques is warranted.

\section{DISCLOSURE}

\section{All authors disclosed no financial relationships rele- vant to this publication.}

Abbreviation: TEF, tracheoesophageal fistula.

\section{REFERENCES}

1. Muniappan A, Wain JC, Wright CD, et al. Surgical treatment of nonmalignant tracheoesophageal fistula: a thirty-five year experience. Ann Thorac Surg 2013;95:1141-6.

2. Kaur D, Anand S, Sharma P, et al. Early presentation of post intubation tracheoesophageal fistula: perioperative anesthetic management. J Anaesthesiol Clin Pharmacol 2012;28:114-6.

3. Chauhan SS, Long JD. Management of tracheoesophageal fistulas in adults. Curr Treat Options Gastroenterol 2004;7:31-40.

4. Dogan UB, Akin MS, Yalaki S. Endoscopic closure of tracheoesophageal fistulas with the over-the-scope clip system. J Coll Physicians Surg Pak 2014;24:S193-5.

5. Silon B, Siddiqui AA, Taylor LJ, et al. Endoscopic management of esophagorespiratory fistulas: a multicenter retrospective study of techniques and outcomes. Dig Dis Sci 2017;62:424-31.

6. Richter GT, Ryckman F, Brown RL, et al. Endoscopic management of recurrent tracheoesophageal fistula. J Pediatr Surg 2008;43:238-45.

7. Bruch SW, Hirschl RB, Coran AG. The diagnosis and management of recurrent tracheoesophageal fistulas. J Pediatr Surg 2010;45:337-40.

Division of Gastroenterology and Hepatology, Mayo Clinic, Jacksonville, Florida, USA.

Copyright (c) 2017 American Society for Gastrointestinal Endoscopy. Published by Elsevier Inc. This is an open access article under the CC BYNC-ND license (http://creativecommons.org/licenses/by-nc-nd/4.0/).

https://doi.org/10.1016/j.vgie.2017.09.009 